\title{
DESENVOLVIMENTO URBANO NO MUNICÍPIO DE SERRA TALHADA, PERNAMBUCO, BRASIL: AVALIAÇÃO DOS IMPACTOS SOCIAIS E AMBIENTAIS PROVOCADOS PELO PROCESSO DE EXPANSÃO URBANA.
}

\author{
Felipe Luiz Lima de Paulo ${ }^{1}$
}

Janielle do Amaral Alves ${ }^{2}$

\author{
Silvia Sibele da Mota e Silva ${ }^{3}$
}

\begin{abstract}
RESUMO
A expansão da rede urbana sem o devido planejamento ocasiona problemas ambientais também nas cidades brasileiras. No município de Serra Talhada, Pernambuco (PE), Brasil, esta dinâmica do desenvolvimento urbano não é diferente, pois apresenta vários aspectos de insustentabilidade para a vida humana. Dessa forma, este artigo tem como objetivo principal avaliar os impactos sociais e ambientais provocados pelo processo de expansão urbana no município de Serra Talhada $-P E$. $A$ investigação ora proposta, quanto aos fins, pode ser caracterizada como uma pesquisa descritiva e, ao mesmo tempo, aplicada. Do ponto de vista dos meios de investigação, a pesquisa se apresenta como de campo e documental. Como resultados, no que diz respeito aos aspectos sociais, constatou-se que os novos espaços urbanos carecem de equipamentos básicos de serviço público. Já nos aspectos ambientais, observou-se que o processo de urbanização no município vem afetando significativamente a saúde, segurança, bem-estar da população, degradando também a biota e qualidade dos recursos naturais, assim como, as condições estéticas e sanitárias do meio ambiente.
\end{abstract}

PALAVRAS-CHAVE: Expansão Urbana, Impactos Sociais e Ambientais, Serra Talhada/Pernambuco/Brasil.

\footnotetext{
${ }^{1}$ Mestre em Gestão do Desenvolvimento Local Sustentável - Universidade de Pernambuco. Professor Assistente, Universidade Federal Rural de Pernambuco (UFRPE) - Unidade Acadêmica de Serra Talhada (UAST); Fazenda Saco s/n caixa postal 063 - Serra Talhada - PE; felipe@uast.ufrpe.br

2 Estudante do Curso de Pós Graduação em Educação Ambiental e Sustentabilidade no Semiárido de Pernambuco; Departamento de Administração (DADM); Universidade Federal Rural de Pernambuco (UFRPE) - Unidade Acadêmica de Serra Talhada (UAST); Fazenda Saco, s/n. Caixa postal 063 Serra Talhada - PE, janielle_amaral@hotmail.com

${ }^{3}$ Mestranda em Consumo, Cotidiano e Desenvolvimento Social - Universidade Federal Rural de Pernambuco. Bolsista da CAPES. silvia_sibele@hotmail.com
} 


\title{
URBAN DEVELOPMENT IN THE CITY OF SERRA TALHADA, PERNAMBUCO, BRAZIL: ASSESSMENT OF THE SOCIAL AND ENVIRONMENTAL IMPACTS CAUSED BY URBAN EXPANSION PROCESS.
}

\begin{abstract}
The expansion of the urban network without proper planning also causes environmental problems in Brazilian cities. Serra Talhada, Pernambuco (PE), Brazil, this dynamic urban development is no different, it presents various aspects of unsustainability for human life. Thus, this article aims to assess the social and environmental impacts caused by urban expansion process in Serra Talhada - PE. The research proposed here, as the purpose can be characterized as a descriptive and at the same time applied. From the point of view of the research funds, the research is presented as field and documentary. As a result, with regard to social aspects, it was found that the new urban spaces lack basic equipment of public service. Already on environmental aspects, it was observed that the process of urbanization in the municipality has significantly affecting the health, safety and welfare of the population, and is also degrading biota and quality of natural resources, as well as the aesthetic and sanitary conditions of the environment.
\end{abstract}

KEY-WORDS: Urban Expansion, Environmental and Social Impact, Serra Talhada / Pernambuco / Brazil.

\section{EL DESARROLLO URBANO EN LA CIUDAD DE SERRA TALHADA, PERNAMBUCO, BRASIL: EVALUACIÓN DE LOS IMPACTOS AMBIENTALES Y SOCIALES CAUSADOS POR EL PROCESO DE EXPANSIÓN URBANA.}

\begin{abstract}
RESUMEN
La expansión de la red urbana sin planificación adecuada también causa problemas medioambientales de las ciudades brasileñas. Serra Talhada, Pernambuco (PE), Brasil, este desarrollo urbano dinámico no es diferente, presenta varios aspectos de la insostenibilidad de la vida humana. Por lo tanto, este artículo tiene como objetivo evaluar los impactos sociales y ambientales causados por proceso de expansión urbana en Serra Talhada - PE. La investigación propuesta aquí, ya que el propósito puede ser caracterizado como un descriptivo y al mismo tiempo aplicado. Desde el punto de vista de los fondos de investigación, la investigación se presenta como campo y documental. Como resultado, en lo que respecta a los aspectos sociales, se encontró que los nuevos espacios urbanos carecen de equipos básicos de servicio público. Ya en los aspectos ambientales, se observó que el proceso de urbanización en el municipio ha afectar significativamente a la salud, la seguridad y el bienestar de la población, y también está degradando la biota y la calidad de los recursos naturales, así como la estética y las condiciones sanitarias de la medio ambiente.
\end{abstract}

PALABRAS-CLAVE: Expansión Urbana, Medio Ambiente e Impacto Social, Serra Talhada / Pernambuco / Brasil. 


\section{INTRODUÇÃO}

A expansão urbana nas cidades é um tema que passa por diversas contradições, pois há uma grande variedade de legislação que permeia o planejamento urbano, bem como a sua ordem e gestão. Através do Plano Diretor e de outras medidas, a cidade muitas vezes não corresponde ao que está estabelecido na lei, tendo em vista a falta de infraestrutura, péssimas condições de vida para populações de baixa renda, ocupação irregular do solo.

As delimitações e planejamento das áreas de zoneamento, muitas vezes favorece a população que possui renda considerável para compra de imóveis dentro da zona urbana e nas melhores localidades, isto é, locais que possuem rede de saneamento básico, redes de água e energia elétrica, pavimentação etc. (BRASIL, 2001). Cabendo a uma parte considerável da população, de baixa renda, migrar para áreas mais distantes dos centros urbanos, buscando abrigo e moradia para suas famílias, sem dispor, em sua grande maioria, de boas condições de infraestrutura nesses locais de ocupação, que por vezes são irregulares e/ou clandestinos.

É perceptível que a expansão da área urbana provoca diversos problemas desde o social até o ambiental, pois muitas vezes não se faz análise dos impactos ambientais provocados por uma nova ocupação do solo, levando o ambiente a grande degradação ambiental.

Ultimamente é bastante visível a elevação de venda e compra de imóveis em todo o país, sobretudo nas cidades onde possui estruturas básicas de crescimento e desenvolvimento econômico.

No município de Serra Talhada, Pernambuco, esta dinâmica de desenvolvimento urbano não é diferente. Nos últimos anos, com a recente chegada de investimentos públicos nas áreas de educação, saúde e infraestrutura, como por exemplo, com a chegada da Universidade Federal Rural de Pernambuco (Unidade Acadêmica de Serra Talhada - PE), das obras da transposição do Rio São Francisco, das obras da Transnordestina e dos investimentos na área de saúde (considerada como um dos importantes polos médicos para a região), o processo de expansão urbana apresenta vários aspectos de insustentabilidade para a vida humana. 
Dessa forma, este artigo tem como objetivo principal o de avaliar os impactos sociais e ambientais provocados pelo processo de expansão urbana no município de Serra Talhada - PE.

\section{URBANIZAÇÃO E CRESCIMENTO DAS CIDADES}

O processo de crescimento urbano consequência da industrialização no Brasil, nas últimas décadas, a partir dos anos 60 , foi o fator primordial para que o país deixasse de ser em sua maioria rural, para se tornar um país com elevado número de habitantes em áreas urbanas, de forma, que a habitação e melhorias na infraestrutura e qualidade de vida tornou-se uma preocupação aparente para o Governo.

Levando em consideração que a ocupação das cidades por a onda de migrações, não foram acompanhadas por politicas públicas cabíveis, ocasionando grandes problemas, que até hoje são visíveis nas cidades. Dessa forma, a expansão urbana se expande por áreas cada vez mais distantes dos grandes centros urbanos, em busca de locais vazios que possam suprir a demanda migratória. Essa expansão imobiliária nos dias atuais não garante moradia apenas para as classes mais baixas, mas também as classes médias e altas, demonstrando, assim, que as fronteiras urbanas possuem tendência de expansão ainda maior (BALBIM; CAMPAGNER, 2011).

Com níveis de crescimento cada vez maior nas cidades e falta de acompanhamento por parte dos órgãos responsáveis, verifica-se grande desigualdade na estrutura espacial dos novos locais de habitação, onde, a população que possui maior poder aquisitivo localiza-se em locais privilegiados, com boa infraestrutura, enquanto, que a população de baixa renda, se estabelece em lugares carentes dos serviços básicos (COSTA, 2003).

De acordo com Santos (2005), os padrões mínimos de urbanidade colaboram para a elevação do preço de terrenos onde há melhorias estruturais. Baltrusis (2006) faz referência e esse mesmo contexto: 


\begin{abstract}
O preço dos terrenos varia de acordo com a sua localização: aqueles melhor localizados, com infraestrutura e com serviços públicos, alcançam melhores ofertas. No entanto, esse preço que o proprietário particular se apropria é fruto do investimento coletivo. Ou seja, o incremento no valor de uma propriedade particular urbana se dá através da apropriação indevida do investimento, que é público (BALTRUSIS, 2006, p. 124).
\end{abstract}

Percebe-se que a especulação imobiliária, possui relação aleatória aos donos da terra, visto que são os investimentos públicos que proporcionam a valorização dos terrenos e consequentemente o seu valor monetário. Assim como, os investimentos em um progresso econômico cada vez maior nas cidades faz com que o mercado de imóveis mantenha-se aquecido.

\title{
2.1.1 ESPECULAÇÃO IMOBILIÁRIA
}

De acordo com Campos Filho (2001, p. 48) a especulação imobiliária pode ser definida, em termos gerais, como "[...] uma forma pela qual os proprietários de terra recebem uma renda transferida dos outros setores produtivos da economia, especialmente através de investimentos públicos na infraestrutura e serviços urbanos [...]".

Conforme o crescimento das cidades se eleva, são necessários espaços novos implicando na expansão urbana. Bem como, emerge em meio a esse cenário - os promotores imobiliários - esses por sua vez, realizam incorporações, construções, compra e venda de imóveis, práticas que são muitas vezes voltadas para as classes mais favorecidas, as que não possuem condições necessárias para a compra do imóvel, sujeitam-se a buscar outras formas de moradia, como favelas ou invasões em terrenos de posse pública ou privada (FÜHR; DIAS, 2013).

Sabe-se que nos dias atuais os imóveis são as melhores formas de investimento, porque possuem tendência de valorização com o decorrer do tempo. Pensando assim, os proprietários de terrenos em áreas urbanas nem sempre fazem o uso correto de imóveis vazios, conhecidos como terrenos baldios, deixando-os para valorização, obrigando as pessoas a se deslocarem para outras localidades, muitas vezes distantes, expandindo o perímetro urbano, bem como, a infraestruturas necessárias nessas novas localidades (BOMFATI; SILVA, 2004) 


\begin{abstract}
O solo urbano tem um grande valor econômico, social e ambiental, pois neles ou em seu entorno, existe trabalho e os lotes urbanos têm um preço de mercado como objetos comercializáveis. Os terrenos urbanos são objetos de compra e venda sujeitos, portanto, às leis que regem o mercado, com a grande desigualdade social muitas vezes os requisitos legais são violados e traz as grandes consequências no crescimento das grandes cidades (GONZALES et al., 1985, apud NASCENTE; FERREIRA, 2007, p. 5)
\end{abstract}

Percebe-se que a especulação imobiliária traz consequências drásticas para o meio social e ambiental, uma vez que, esperam o melhor momento para a comercialização dos terrenos, que muitas vezes se sobrecarregam e não atende as estruturas desejadas, além do elevado preço das áreas valorizadas pela infraestrutura municipal.

Costa (2003) acredita que as cidades embora sejam construídas de forma coletiva, os serviços oferecidos a sociedade não são atendidos por todas as pessoas, dessa forma, é necessário haver uma reformulação nas políticas urbanas e implantar programas e ações que favoreçam a todos de forma homogênea.

\title{
2.1.2 POLÍTICAS HABITACIONAIS
}

A Política Nacional de Desenvolvimento Urbano, de responsabilidade do Ministério das Cidades, tem como princípio a habitação de interesse social, que buscam soluções de habitação e moradia para pessoas carentes. Desde o ano de 2003, foram pensados e criados programas novos como o "Crédito Solidário, em 2004, o PAC Urbanização de Favelas, em 2007, e o Minha Casa Minha Vida, em 2009" (IPEA, 2011, p.4).

Silva e Andrade (2014) acreditam que o Programa Minha Casa, Minha Vida, nos dias atuais, é o principal responsável pelo aumento considerável de habitações nas áreas urbanas, ao mesmo tempo em que impulsiona o mercado da construção civil, gera empregos e tem como principal objetivo diminuir o déficit habitacional, proporcionando as famílias de classe baixa à sua casa própria.

O público-alvo são famílias com renda até 10 salários mínimos, sendo que as famílias com renda até três salários mínimos podem ter acesso a subsídio integral com isenção do seguro; as famílias com renda de 3 a 6 salários 
mínimos tem aumento do subsídio parcial em financiamentos com redução dos custos do seguro e acesso ao Fundo Garantidor; já as famílias com renda de 6 a 10 salários mínimos têm estímulo à compra com redução dos custos do seguro e acesso ao Fundo Garantidor (MINISTÉRIO DAS CIDADES, 2014).

O problema que se constata com tamanha amplitude desse programa é a expansão em áreas cada vez maiores, ocasionando a degradação do meio ambiente, além de um mau planejamento por parte dos órgãos municipais implicando em perigo para a sustentabilidade.

No que diz respeito também ao processo de políticas públicas para habitação das pessoas mais carentes, observa-se também que as mesmas se mostram muitas vezes fragmentadas, sem observar as várias dimensões do desenvolvimento urbano mais humano (como construções de conjuntos habitacionais inter-relacionados com a formação profissional, manutenção dos vínculos com a cidade, respeito às especificidades culturais dos moradores transferidos e o acompanhamento do processo de adaptação à nova condição ${ }^{4}$ ). Neste aspecto, no município de Recife-PE, por exemplo, Castilho (2012), menciona que várias pesquisas demonstraram que o programa de erradicação de palafitas ainda não estava conseguindo promover mudanças efetivas:

(...) simplesmente porque o mero deslocamento de famílias de certos ambientes como os de palafitas - com condições insalubres - para outros, sem as garantias necessárias à existência das pessoas nos "seus" novos ambientes, acaba piorando ainda mais as suas condições de vida. (CASTILHO, 2012, p. 199).

Este tipo de política pública, mencionada pelo autor citado, corrobora com a ideia de que tais políticas necessitam de uma abordagem mais interdisciplinar desde o momento de sua concepção. As formas de gestão e governança das cidades ainda são muitas vezes colocadas em prática de forma fragmentada, apesar do processo de democratização do país após a constituição de 1988. Percebe-se, ainda, que existe influência das elites econômicas que corroboram para perpetuar problemas sociais de pobreza urbana e exclusão social (LEAL, 2012).

\footnotetext{
${ }^{4}$ Inter-relações ideais em política pública de habitação de interesse social (CASTLHO, 2010/2013).
} 


\title{
3 IMPACTOS AMBIENTAIS OCASIONADOS PELA EXPANSÃO URBANA
}

De acordo com a Resolução no 01/86 do Conselho Nacional do Meio Ambiente - CONAMA:

\author{
Considera-se impacto ambiental qualquer alteração das propriedades físicas, \\ químicas e biológicas do meio ambiente, causada por qualquer forma de \\ matéria ou energia resultante das atividades humanas que, direta ou \\ indiretamente, afetam: \\ I - a saúde, a segurança e o bem-estar da população; \\ II - as atividades sociais e econômicas; \\ III - a biota; \\ IV - as condições estéticas e sanitárias do meio ambiente; \\ $\mathrm{V}$ - a qualidade dos recursos ambientais. (BRASIL, 2014).
}

Sendo assim, entende-se por impacto ambiental tudo que causa alteração do meio, decorrente de ações antrópicas. Que podem em proporções maiores ou menores, comprometer a segurança e a saúde das pessoas, bem como, o bem estar dos recursos naturais e dos seres que deles dependem (FERREIRA et. al., 2005).

O ser homem para satisfazer suas necessidades tem ocasionado, ao longo dos anos, diversas alterações ao meio ambiente, na exploração de recursos naturais para produção de bens, assim como, para construir habitações provocando o aceleramento da urbanização, desencadeando diversos problemas ambientais como os resíduos sólidos e o descarte inadequado, poluição.

Ferreira et al. (2005) acredita que as principais alterações no meio ambiente podem ser o desmatamento, impermeabilização do solo, assoreamento dos rios, alterações nos ecossistemas, além dos principais problemas ambientais a nível global, o efeito estufa, a destruição da camada de ozônio etc.

A consequência da urbanização sobre os ecossistemas vem provocando grande degradação ambiental seja em cidades de pequeno e/ou médio porte, demonstrando uma situação preocupante no que se refere ao planejamento dos municípios (SOARES et. al., 2006).

Para Costa (2003) o poder público, deve ser o principal responsável por regular e buscar soluções que minimizem problemas do tipo, sejam eles ambientais ou não, além do que, deve proporcionar a população urbana boa infraestrutura e serviços adequados, viabilizando uma boa qualidade de vida. 


\section{METODOLOGIA}

\subsection{CARACTERIZAÇÃO DA ÁREA DE ESTUDO}

O Município de Serra Talhada está localizado no Estado de Pernambuco - PE, Brasil. Especificamente, localiza-se na mesorregião do Sertão Pernambucano, Microrregião do Sertão do Pajeú. Em relação a capital do Estado de Pernambuco, Serra Talhada - PE está a cerca de 420 km de distância e seu principal acesso é pela BR 232. Em relação à população, o último censo do IBGE (ano 2014) consta que o município possui população estimada de 83.712 .

Em relação à vegetação do município, pode-se dizer que é basicamente composta por caatinga hiperxerófila. Já o clima é do tipo semiárido, com poucos períodos de precipitação e temperatura média de $25^{\circ} \mathrm{C}$.

Serra Talhada - PE também é considerado um dos principais polos médicos do Estado de Pernambuco e o principal município em relação à economia da região em que está localizado. Concentra-se no setor de serviços, com destaque nas áreas de comércio, lazer e cultura (considerada neste aspecto como sendo a capital do xaxado).

\subsection{MATERIAIS E MÉTODOS}

Com base nos tipos de pesquisa sugerida por Vergara (1998, p. 44), a pesquisa realizada, quanto aos fins, pode ser caracterizada como descritiva e, ao mesmo tempo, aplicada. Descritiva, porque buscou mostrar a situação do município de Serra Talhada, Pernambuco, Brasil, quanto aos danos provocados pelas atividades humanas em seus territórios provenientes do processo de expansão urbana. Ao mesmo tempo, pode ser classificada como uma pesquisa aplicada, pois visa a contribuir para mudanças na atuação do governo local por meio da divulgação dos resultados desta pesquisa para os gestores do município (PEDROSA, et al. 2013) 
Do ponto de vista dos meios de investigação, segundo a mesma autora, a pesquisa se apresenta como de campo e documental. De campo, porque houve coleta de dados da paisagem do espaço natural por meio de visita in loco (registrados em alguns momentos por meio de fotografias). Documental, porque foram examinados o plano diretor do município de Serra Talhada - PE e outros documentos (tais como leis municipais).

\section{RESULTADOS E DISCUSSÃO}

5.1 O PROCESSO DE EXPANSÃO URBANA NO MUNICÍPIO DE SERRA TALHADA $-P E$

Desde o ano 1851, quando o município de Serra Talhada - PE se emancipava politicamente, há 163 anos, que o processo de uso e ocupação do solo urbano vem sofrendo mudanças. Seguindo uma ideia malthusiana, talvez pessimista, de que os recursos são escassos em detrimento ao crescimento populacional, o município sofreu várias alterações nos aspectos sociais e ambientais principalmente no que diz respeito à paisagem urbana.

A antiga Villa Bela, hoje o município de Serra Talhada - PE sofreu mudanças políticas, econômicas e ambientais ao longo do tempo. Hoje considerado um dos principais municípios da região do Sertão do Pajeú, é considerado um importante polo médico e educacional para os demais municípios de porte menor da região. Ressaltese também que é um dos principais municípios da região que movimenta a economia local principalmente no setor de serviços entre micro e pequenas empresas.

Contudo, nos últimos anos ocorreu um maior impacto para a expansão urbana no município, advinda principalmente por alguns fatores, tais como: chegada da Universidade Federal Rural de Pernambuco - Unidade Acadêmica de Serra Talhada em agosto de 2006 (advinda do processo de interiorização do ensino superior federal), obras da ferrovia Transnordestina que liga os estados do Piauí ao Ceará (principalmente a do lote que liga os municípios de Serra Talhada - PE a Salgueiro PE) para o escoamento de mercadorias, e, recentemente com perspectiva ainda maiores de crescimento com a chegada do curso de medicina da Universidade de Pernambuco e do Instituto Federal de Educação. Atreladas a tudo isso, observa-se 
também a expansão de serviços essenciais para a população, tais como saúde, alimentação, vestuário, e outros.

Contudo, este fenômeno, acabou fazendo com que houvesse migração populacional para a região, impactando na estrutura urbana antes predominantemente de município de interior. Inicialmente observou-se aumento nos preços dos alugueis, no valor dos imóveis, na verticalização dos imóveis, ou seja, do uso e ocupação do solo em geral, principalmente naquelas áreas já delimitadas como valorizadas, seja por ter maior disponibilidade de equipamentos de serviços públicos e privados, ou por historicamente terem sido ocupadas por aqueles que possuem maior poder aquisitivo.

Este fenômeno fez com que vários moradores, com menor poder aquisitivo, deixassem suas residências (vendendo ou alugando) em detrimento do poder econômico. Neste sentido, ao analisar a paisagem urbana atual, ainda observa-se um exemplo de moradia antiga em meio a um dos bairros mais nobres do município (foto 1). Observe-se que a estrutura apresentada (casa de pau a pique ${ }^{5}$ ) não condiz nem de longe com as atuais estruturas de edificações hoje feitas.

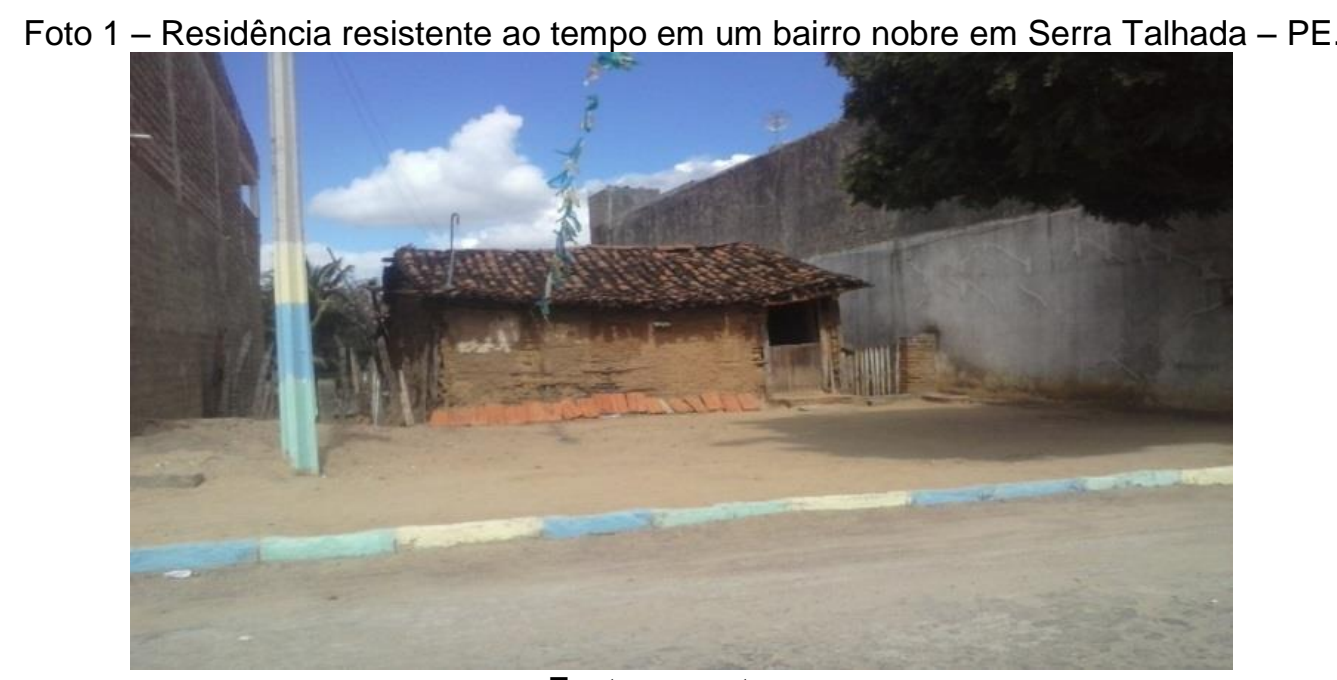

Fonte: os autores

\footnotetext{
5 Uma técnica construtiva antiga que consistia no entrelaçamento de madeiras verticais fixadas no solo, com vigas horizontais, geralmente de bambu amarradas entre si por cipós, dando origem a um grande painel perfurado que, após ter os vãos preenchidos com barro, transformava-se em parede. Podia receber acabamento alisado ou não, permanecendo rústica, ou ainda receber pintura de caiação.
} 
Problemática deste fenômeno, de deslocamento da população antes residentes na área urbana já estabelecida, para outras áreas de expansão, reside justamente nos problemas sociais e ambientais que serão elencados a seguir. Ressalte-se que recentemente foi aprovada a lei complementar $n^{\circ} 235$ de 29/07/2014 (lei municipal) que aprovou novas descrições dos limites do zoneamento urbano (decorrente do crescimento espontâneo da área urbana nos últimos anos).

\subsection{IMPACTOS SOCIAIS PROVOCADOS PELO PROCESSO DE EXPANSÃO} URBANA NO MUNICÍPIO DE SERRA TALHADA - PE

Com o fenômeno de migração da população mais carente do município de Serra Talhada - PE para algumas áreas de expansão, incentivadas na maioria dos casos pelo programa Minha Casa Minha Vida do governo federal, começaram a surgir problemas de cunho social. Primeiramente, em muitos casos, estes espaços carecem de equipamentos básicos de serviço público, tais como: calçamento, transporte público com qualidade mínima para deslocamento para o centro do município e outras áreas, saneamento básico e serviço adequado de coleta de lixo. Outros serviços, tais como acesso a internet, por exemplo, também carecem de acesso pleno pela população. Importante ressaltar, que algumas novas construções vêm apresentando problemas estruturais (como rachaduras, por exemplo).

No que diz respeito ao fenômeno da política fragmentada apresentada por Castilho (2012) na condução do deslocamento da população das palafitas para outras áreas na região metropolitana do Recife, pode-se dizer que no município de Serra Talhada - PE também há indícios deste fenômeno. Populações preferem fixar residência em áreas insalubres por simplesmente estar próximas do ambiente de trabalho, como é o caso dos catadores de materiais recicláveis que fixam residência no lixão (figura 2). 


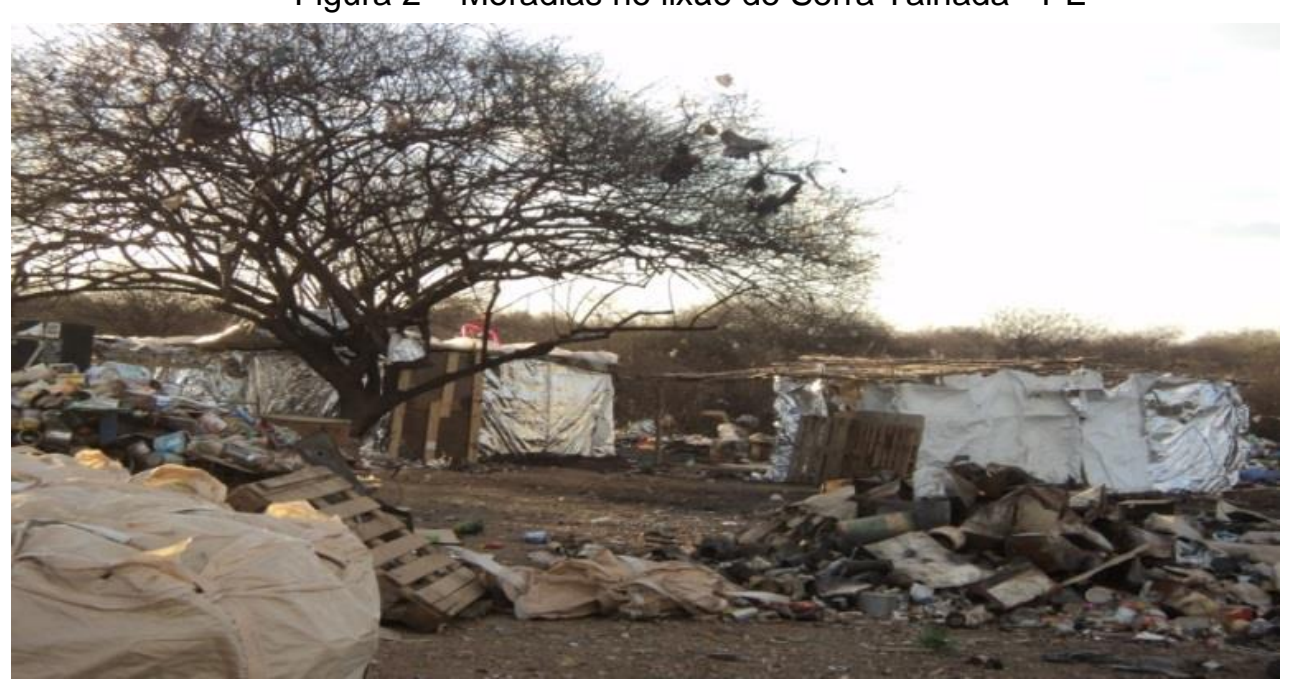

Fonte: os autores

Ou seja, não adianta ampliar o acesso ao crédito, por menor que seja a parcela para pagamento, como se propõe nos programas governamentais para habitação popular, se não há garantia de acesso urbano humano sem inter-relacionar estes novos espaços com a formação profissional, manutenção dos vínculos com a cidade, respeito às especificidades culturais dos moradores transferidos e o acompanhamento do processo de adaptação à nova condição.

\subsection{IMPACTOS AMBIENTAIS PROVOCADOS PELO PROCESSO DE EXPANSÃO URBANA NO MUNICÍPIO DE SERRA TALHADA - PE}

No que diz respeito aos impactos ambientais provocados pelo processo de expansão urbana no município de Serra Talhada - PE, pode-se dizer que muitos daqueles mencionados como impacto social, também será aqui evidenciado como agressão ao meio ambiente, tal como preconiza a Resolução no 01/86 do Conselho Nacional do Meio Ambiente - CONAMA.

$O$ processo de urbanização no município vem afetando significativamente a saúde, segurança, bem-estar da população, vem degradando também a biota e qualidade dos recursos naturais e condições estéticas e sanitárias do meio ambiente (apesar de tudo isso ser contraditório ao que é disposto no artigo $2^{\circ}$ do Plano Diretor do município - Lei Complementar $n^{\circ}$ 052, 22/01/2007, quando diz que "é o 
instrumento básico da política de desenvolvimento e expansão urbana e integra o processo de planejamento sustentável e gestão municipal").

No que diz respeito à saúde, segurança e bem-estar da população, pode-se dizer que as áreas de expansão por serem mais distantes do centro do município (onde se concentram as atividades econômicas da cidade) atreladas à prestação de serviços de transporte público urbano sem qualidade mínima, afeta significativamente o bem-estar da população. Enfatiza-se, também, o aumento da violência urbana nestas áreas e o acesso precário aos serviços básicos de saúde e de saneamento.

No que diz respeito à biota e a qualidade dos recursos naturais, pode-se dizer que há, em meio ao processo de expansão urbana, o fenômeno dos loteamentos irregulares, ou seja, aqueles espaços que são ocupados irregularmente pela população sem qualquer tipo de planejamento urbano e social. Primeiramente há a devastação da caatinga para delimitar os espaços (fato já em fase de análise pelos órgãos competentes do município e estado de Pernambuco). Observe-se, também, a degradação do rio Pajeú no lançamento de dejetos vindos muitas vezes dos matadouros. Estes dejetos também são lançados de forma irregular nos lixões (apesar da Política Nacional de Resíduos Sólidos ter instituído o fechamento dos lixões até 2014), conforme pode ser visto na figura 3.

Figura 3 - Resíduos de animais dos matadouros no lixão do município de Serra Talhada - PE.

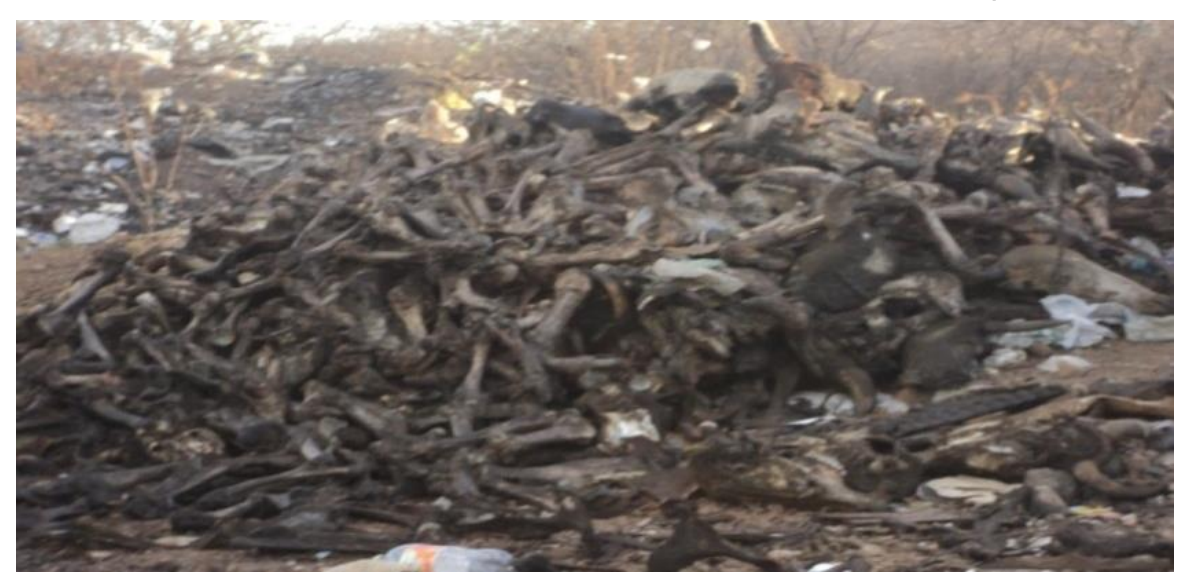

Fonte: os autores 
No que diz respeito, ainda, em relação ao tratamento dos resíduos sólidos urbanos, observe-se também que não há tratamento adequado de forma plena pelo governo local com relação aos resíduos domiciliares, apesar de haver uma iniciativa de uma organização não governamental para o tratamento de materiais recicláveis (PAULO, SANTOS E SILVA, 2013). Em visita recente ao lixão (figura 4) pode-se observar a queimada do lixo domiciliar e também hospitalar naquele espaço.

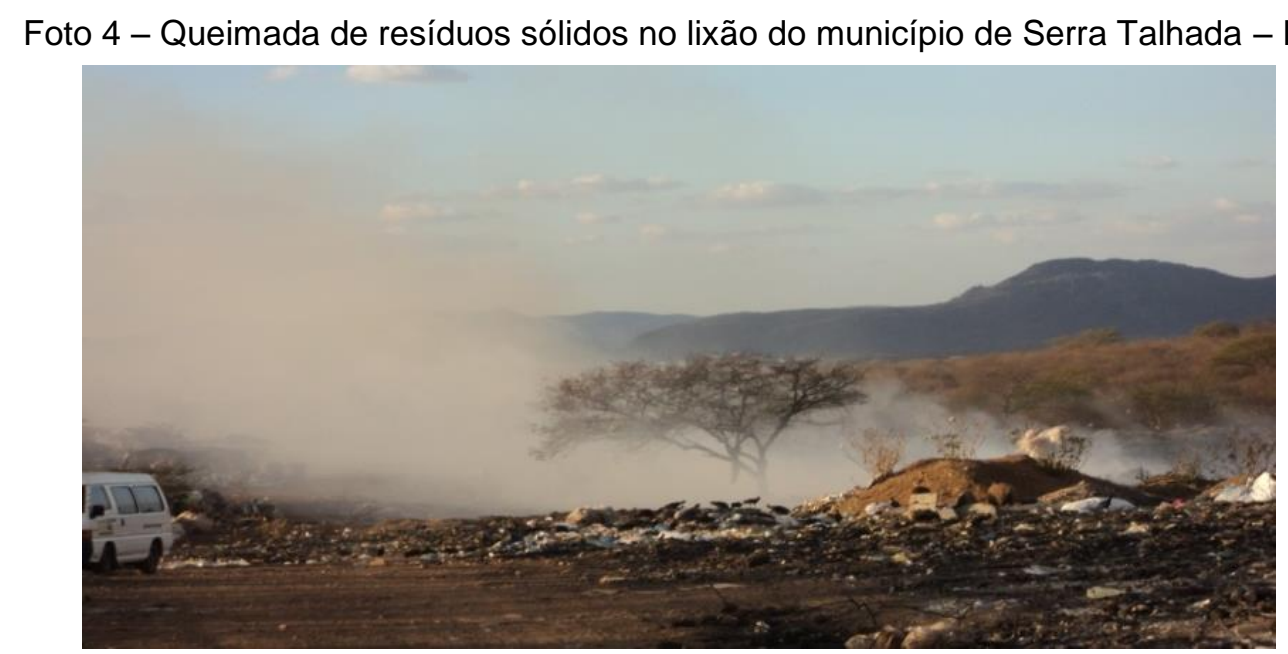

Fonte: os autores

Como se pode observar, isso afeta a condição estética e a qualidade do ar para a população do município de Serra Talhada -PE. Contudo, embora todos estes impactos ambientais, uma ação positiva no município foi à delimitação da mata da pimenteira como uma unidade de conservação da natureza (localizada próxima da Universidade Federal Rural de Pernambuco, Unidade Acadêmica de Serra Talhada).

\section{CONCLUSÃO}

O objetivo principal deste artigo foi o de avaliar os impactos sociais e ambientais provocados pelo processo de expansão urbana no município de Serra Talhada - PE.

No que diz respeito ao processo de expansão urbana no município, observouse que o maior crescimento se deu nos últimos anos devido principalmente ao forte 
investimento público nas áreas de educação e infraestrutura, e este crescimento afetou significativamente os aspectos sociais e ambientais do município.

Em relação aos aspectos sociais, constatou-se que os novos espaços urbanos carecem de equipamentos básicos de serviço público, tais como: calçamento, transporte público com qualidade mínima para deslocamento para o centro do município e outras áreas, saneamento básico e serviço adequado de coleta de lixo, por exemplo.

Já nos aspectos ambientais, observou-se que o processo de urbanização no município vem afetando significativamente a saúde, segurança, bem-estar da população, assim como, degradação da biota e qualidade dos recursos naturais e condições estéticas e sanitárias do meio ambiente.

Por fim, espera-se que trabalhos futuros possam aprofundar as lacunas deixadas por este trabalho, especialmente quanto ao processo de governança do setor público municipal para o enfrentamento dos problemas apresentados.

\section{REFERÊNCIAS}

BALBIM, Renato; CAMPAGNER, Larissa. Desenvolvimento urbano, o uso de instrumentos adaptados. O caso das operações urbanas em São Paulo. II Code. Anais do I Circuito de Debates Acadêmicos, 2011. Brasília

BALTRUSIS, N. A valorização fundiária da propriedade urbana. Cadernos Metrópole, São Paulo, n. 16, p. 121-139, 2006.

BEltrão, N. E. de M., CARTAXO, W. V., PEREIRA, S. R. P., SOARES, J. J., SiLVA, O. R. R. F. O cultivo sustentável da mamona no Semi-árido Brasileiro. Campina Grande: EMBRAPA-CNPA, 2005. 23 p. (EMBRAPA-CNPA. Circular Técnica, 84).

BOMFATI, Eric; SILVA, Maclovia Corrêa da. Os impactos sociais e ambientais do crescimento econômico no território urbano: interesses locais entre agentes do setor privado na cidade de Ponta Grossa - PR. Revista Educação \& Tecnologia. Curitiba, CEFET-PR, v. 8, p. 18 -208, 2004.

BRASIL. Resolução CONAMA no. 001/86 Define Impacto Ambiental. Disponível em: http://www.mma.gov.br/port/conama/res/res86/res0186.html.

. Estatuto da cidade (2001). Estatuto da cidade: Lei n. 10.257, de 10 de julho de 2001, que estabelece diretrizes gerais da política urbana. Brasília: Câmara dos Deputados, Coordenação de Publicações, 2001. 35 p.

CAMPOS FILHO, Candido Malta. Cidades brasileiras: seu controle ou o caos. 4 ed. São Paulo: Studio Nobel, 2001. 
CASTILHO, Cláudio Jorge Moura de. A (In) Sustentabilidade da Vida Humana nas Cidades: Redirecionamentos Teórico-Metodológicos à Construção de Ambientes Urbanos Humanos. Revista Brasileira de Geografia Física, v. 5, p. 185-206, 2012.

COSTA, Ademir Araújo da. Crescimento urbano e problemas socioespaciais: um estudo da periferia de Natal. Mercator - Revista de Geografia da UFC, v. 2, n. 4, p. 57-61, 2003.

FERREIRA, Daniela Figueiredo; SAMPAIO, Francisco Edison; SILVA, Reinaldo Vieira da Costa; MATTOS, Sílvio Costa. Impactos socioambientais provocados pelas ocupações irregulares em áreas de interesse ambiental - Goiânia/GO. Artigo (Pós-graduação em Gestão Ambiental). Universidade Católica de Goiás, 2005.

FÜHR, Josiane de Oliveira Medeiros; DIAS, Edson dos Santos. Impactos socioambientais provocados pelo processo de expansão urbana de Marechal Cândido Rondon-PR. Revista Perspectiva Geográfica, Unioeste, v.8, n. 9, 2013.

IBGE. Cidades. Disponível em < http://cidades.ibge.gov.br/xtras/perfil.php?codmun=261390>. Acesso em 7 set. 2014.

IPEA. O planejamento da habitação de interesse social no Brasil: desafios e perspectivas, n. 118, out. 2011.

LEAL, Suely Maria Ribeiro. Papel dos Atores Econômicos na Governança das Cidades Brasileiras. Revista Movimentos Sociais e Dinâmicas Espaciais. Recife: UFPE/MSEU, v.01, n1, 2012.

NASCENTE, João Paulo Carneiro; FERREIRA, Osmar Mendes. Impactos socioambientais provocados pelas ocupações irregulares do solo urbano: estudo de caso do loteamento Serra Azul. Goiânia: Universidade Católica de Goiás, 2007.

Paulo, Felipe Luiz Lima ; SANTOS, C. F. ; SILVA, M. N. . A IMPORTÂNCIA DAS COOPERATIVAS DE MATERIAIS RECICLÁVEIS: UM BREVE RELATO DA EXPERIÊNCIA DO MUNICÍPIO DE SERRA TALHADA PE. Tupã: Revista Nacional de Gerenciamento de Cidades, 2013

PEDROSA, Ivo V. ; PAULO, Felipe L. L. de ; Corrêa, Cristiano ; MONTEIRO, Antonio. L. R. ; PEREGRINO, C. F. L. ; Sena, G.I.C. ; OLIVEIRA, I. D. A. C. ; NASCIMENTO, M. F. L. ; COSTA, M. C. N. ; AQUINO, V. A. ; Lucena, Alysson Henrique Ferreira . Os governos municipais e o enfrentamento da crise ambiental: o caso de Pernambuco. 2013. (Relatório de pesquisa).

SANTOS, Milton - A urbanização brasileira. 6 ed., USP, São Paulo, p. 174, 2005.

SILVA, Medelin Lourena da; ANDRADE, Nayan Rodrigues de. Estado e mercado imobiliário: o Projeto "Minha Casa Minha Vida - Coelha" em Viçosa - MG. Caderno de Geografia, v.24, número especial (1), jun. 2014.

SOARES, Thelma Shirlen; CARVALHO, Rosa Maria Miranda Armond; VIANA, Eder Cristiano; ANTUNES, Flávia Corrêa Borges. Impactos ambientais decorrentes da ocupação desordenada na área urbana do município de Viçosa, Estado de Minas Gerais. Revista Científica Eletrônica De Engenharia Florestal, ano IV, n. 08, ago. 2006. 